\title{
Palliative Care and Hospice: A Paradigm for End-of-Life Care in Developing Nations
}

Peter A. Clark, S.J., Ph.D.*

Professor and Director; Institute of Clinical Bioethics, St. Joseph's University, Philaadelphia, USA

\section{DOI Name}

http://dx.doi.org/10.3126/jaim.v6i2.18541

\section{Keywords}

Palliative Care, Hospice Care and Death

Citation

Peter A. Clark. Palliative Care and Hospice: A

Paradigm for End-of-Life Care in Developing Nations. Journal of Advances in Internal Medicine 2017;06(01):38-44

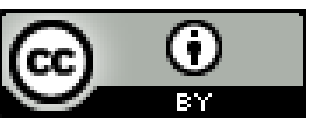

This work is licensed under a Creative Commons Attribution 3.0 Unported License.

\begin{abstract}
Traditionally, medical care has had two mutually exclusive goals: either to cure disease and to prolong life or to provide comfort care. Given this dichotomy, the decision to focus on reducing suffering is made usually only after lifeprolonging treatment has been ineffectual and death is imminent, usually by days or hours. As a result, one of the best kept secrets in a hospital today in the United States is palliative care and hospice care. We estimate that of the 2.4 million Americans that die each year, about $80 \%$ end their lives in hospitals attached to the latest advances in technology; 300,000 die at home under hospice care. The reasons why more people do not receive palliative or hospice care range from the patient's fear of abandonment and the unknown, the family's denial of the inevitability of death of their loved one, and physician's denial of medicine's limitations. Unless the options of palliative or hospice care are given to patients the fears that people have of dying--fear of dying alone and fear of dying in pain--will continue to make the dying process one that lacks dignity and respect. In this review article we have reviewed the state of palliative and hospice care in the United States through a historical, ethical and legal perspective. We have discussed its scope in the developing world and the potential challenges.
\end{abstract}

\section{INTRODUCTION}

"Death is not the ultimate tragedy of life. The ultimate tragedy is depersonalization-dying in an alien and sterile area, separated from the spiritual nourishment that comes from being able to reach out to a living hand, separated from a desire to experience the things that make life worth living, separated from hope."

Traditionally, medical care has had two mutually exclusive goals: either to cure disease and to prolong life or to provide comfort care. Given this dichotomy, the decision to focus on reducing suffering is made usually only after life-prolonging treatment has been ineffectual and death is imminent, usually by days or hours. ${ }^{2}$ As a result, one of the best kept secrets in a hospital today in the United States is palliative care and hospice care. We estimate that of the 2.4 million Americans that die each year, about $80 \%$ end their lives in hospitals attached to the latest advances in technology; 300,000 die at home under hospice care. ${ }^{3}$ The reasons why more people do not receive palliative or hospice care range from the patient's fear of abandonment and the unknown, the family's denial of the inevitability of death of their loved one, and physician's denial of medicine's limitations. Unless the options of palliative or hospice care are given to patients the fears that people have of dying--fear of dying alone and fear of dying in pain--will continue to make the dying process one that lacks dignity and respect.

\section{PALLIATIVE CARE:}

Palliative care comes from the Latin word palliare which means to cloak. It is a form of medical care or treatment that concentrates on reducing the severity of the symptoms of a disease, or to slow the disease progress, rather than provide a cure. Occasionally, it can be used with a curative therapy, providing that the curative therapy will not cause additional morbidity. The goal is to relieve suffering and improve the quality of life for patients with advanced illnesses and their families through scientific knowledge and skills,

\footnotetext{
* Corresponding author:
}

Peter A. Clark, S.J., Ph.D.

The Institute of Clinical Bioethics, St. Joseph's University

Barbelin Hall, 5600 City, Philadelphia, PA 19131, USA; pclark@sju.edu 
including communication with patients and family members; management of pain and other symptoms; psychosocial, spiritual, and bereavement support; and coordination of an array of medical and social services. ${ }^{4}$ The World Health Organization (WHO) in 1990 defined palliative care as "the active care of patients whose disease is not responsive to curative treatment." This definition stresses the terminal nature of the disease. ${ }^{5}$

\section{HOSPICE CARE:}

Hospice care is viewed as part of the philosophy that we call palliative care. Hospice is a centuries old idea coming from the Latin word hospes meaning guest. Originally, it referred to the offering of a place of shelter and rest or what we refer to as "hospitality" to weary and sick travelers on a long journey. Over the centuries it developed into a philosophy of care that recognizes death as the final stage of life and seeks to enable patients to continue an alert, pain-free life and to manage other symptoms so that their last days may be spent with dignity and quality, surrounded by their loved ones. Hospice care like palliative care affirms life and neither hastens or postpones death. The focus of hospice and palliative care is to treat the whole person rather than the disease; it emphasizes quality rather than quantity or length of life. ${ }^{6}$ In addition, emphasis is placed not only on the well-being of the patient but also on the well-being of the family caregivers. Hospice personnel provide care for the patient and the family 24 hours a day, 7 days a week.

The history of hospice and palliative care dates back to ancient times. Some say the first hospice experience appears in the New Testament with the parable of the Good Samaritan (Luke 10: 29-37). The Good Samaritan bandaged the wounds of the man beaten and lying along the roadside, then took him to the closest inn and paid to have the man ministered to by the innkeeper. Others believe the first recorded hospice opened in 475 AD in Syria by Fabiola, a Roman woman and follower of St. Jerome, as a place of rest for the traveler, the sick and the dying. During the next 1500 years, hospices, provided care for those on a journey. In the $19^{\text {th }}$ century a religious order established hospices for the dying in Ireland and London. ${ }^{7}$ "Until the $20^{\text {th }}$ century, most people spent their last days at home, surrounded, cared for, and comforted by family and friends. That tradition faded as hospitals became places of healing in many Western countries." ${ }^{8}$ The modern notion of hospice began in 1967 when Dr. Cicely Saunders founded St. Christopher's Hospice in London. She is regarded as the founder of the modern hospice movement. As a physician, Saunders dedicated her life to the care of the dying and planned a model hospice that would provide exemplary palliative care and would incorporate teaching and research programs. She avowed the regular giving of strong narcotics, including heroin and the Brompron cocktail mixture of morphine and gin, as the proper regimen to ensure that a pain-free patient could maintain quality of life in the last days. St. Christopher's demonstrated the superior reliability and efficacy of oral morphine over heroin and reported the absence of tolerance and addiction in cancer patients, even with long-term use. ${ }^{9}$ The hospice movement in the United States began in the 1960s but the first hospice to provide services was the Connecticut Hospice in March 1974. "In 1982, Congress created the Medicare hospice benefit, reserving such services for terminally ill Medicare beneficiaries with life expectancies of six months or less 'if the disease runs its normal course.' Effective with the enactment of the Balanced Budget Act of 1997, the Medicare hospice benefit was divided into the following benefit periods: 1) an initial 90-day period; 2) a subsequent 90-day period; and 3) an unlimited number of subsequent 60-day benefit periods as long as the patient continued to meet program eligibility requirements. Beneficiaries must be re-certified as terminally ill at the beginning of each benefit period."10 The relatively generous Medicare reimbursement for hospice treatment has increased hospice usage in the United States. The 1989 Congressional mandate increased reimbursement rates by $20 \%$ and tied future increases to the annual increase in the hospital market basket. From 1984 to January 2006, the total number of hospices participating in Medicare rose from 31 to 2,884-a more than $90 \%$ increase [Appendix A]. Of these, 1,648 are freestanding, 672 are home health agency-based, 551 are hospital-based, and 13 are skilled nursing facilitybased. ${ }^{11}$ The first hospital-based palliative care program in the United States began in 1989 at the Cleveland Clinic, in response to the recognition that restrictions on hospice eligibility imposed by the Medicare Hospice Benefit prevented adequate care for seriously ill and dying patients in acute care hospitals. In response, there has been a dramatic increase in hospital-based palliative care programs, now numbering more than $1200 .^{12}$

Hospice programs provide services in various settings: the home, hospice centers, hospitals, or skilled nursing facilities. The number of hospice programs in the United States has continued to increase from the first program in 1974 to more than 4,100 programs today. ${ }^{13}$ The majority of the growth is in small free-standing programs. $93 \%$ of agencies reported that they are Medicare certified; nearly 3 out of 4 hospice programs are accredited by either the Joint Commission on Accreditation of Healthcare Organizations (JCAHO), Community Health Accreditation Program (CHAP), Accreditation Commission for Healthcare $(\mathrm{ACHC})$, or other accrediting agencies. $67.6 \%$ of programs reported nonprofit (501c3) status while $27.2 \%$ 
reported for-profit status. Government-run programs account for $5.2 \%$ of all programs. ${ }^{14}$ The criteria for hospice care under the Medicare benefit requires that patients acknowledge they are in the dying process and are willing to forego insurance coverage for life prolonging treatments and that two physicians certify that the patient has a life expectancy of six months or less. Studies have shown that referral to palliative care programs and hospice results in beneficial effects on patients' symptoms, reduced hospital costs, greater likelihood of death at home, and a higher level of patient and family satisfaction that does conventional care. ${ }^{15}$

The principles that constitute the National Hospice Organization's "Philosophy of Hospice" include:

1) Hospice implies acceptance of death as a natural part of the cycle of life.

2) When death is inevitable, hospice will neither seek to hasten it nor to postpone it.

3) Patients, their families and loved ones are the unit of care.

4) Psychological and spiritual pain are as significant as physical pain, and addressing all three requires the skills and approach of an interdisciplinary team.

5) Pain relief and symptom control are appropriate clinical goals; the goal of all intervention is to maximize the quality of remaining life through the provision of palliative therapies.

6) Care is provided regardless of ability to pay. ${ }^{16}$

The principles of hospice and palliative care are based on a shift in the patient's treatment from curative to palliative care. This shift rarely takes place at a specific moment. "Just as the disease treatment is a process, so to is preparing a patient for the time when treatment for cure is no longer an option. Preparing a patient begins with an honest discussion of the disease and its outcomes." ${ }^{17}$ Physicians have the ethical responsibility to be honest with their patients about their medical condition. When there are no further treatments to cure the disease, the patient must be informed of this fact but must also be given the option of palliative care and hospice care as a treatment. "Presenting hospice as a medical option for treating a terminal illness can help with many unknowns - 'fears of uncontrollable pain, nausea, vomiting, embarrassment and especially abandonment' that often accompany end stage diseases."18 The focus of hospice is to provide services to both patients and their families to assist and support them during the dying process. The family of the patient and others involved with the patient can be crucial in any hospice discussion and care plan. In many cases the patient may be ready to accept hospice care but family members and friends are not. At times, they can even coerce the patient into continuing aggressive treatment even though the burdens outweigh the benefits. That is why the family should be included in these discussions whenever possible but always with the patient's consent. Many times all the family needs to hear is that the patient has accepted the diagnosis of the terminal condition and that it is his or her choice to accept hospice care. ${ }^{19}$ Hospice treats the patient and the family as a unit and unless both parties understand the principles and the goal of hospice, the services offered will fail to be beneficial to all parties concerned.

Hospice services are offered by a multidisciplinary team whose emphasis is to maximize comfort for the terminally ill patient and support the family members and other loved ones. The hospice team consists of physicians, nurses, health care aides, spiritual counselors, social workers, volunteers, ancillary therapists and bereavement counselors. The services offered by the hospice team include: pain and symptom support, spiritual care, home care and inpatient care, respite care, family conferences, bereavement care [Examples can be found in Appendix B, C, $D, E]$. The services offered are extensive and wide-ranging. For example, hospice care integrates complementary therapies with conventional care such as relaxation therapy, massage therapy, music therapy and acupuncture to relieve symptoms and other causes of pain. Trained bereavement counselors offer support and guidance for patients and family members. This support continues for up to a year after the death of the patient. The most common concerns found among those in a terminal condition are: fear of pain, loss of independence, worries about family and feeling like a burden. The hospice team provides comprehensive palliative care aimed at relieving symptoms, treating depression in patients and giving social, emotional and spiritual support to both the patient and the family.

\section{Factual Implications of Palliative Care and Hospice:}

Despite these services only about a third of the 2.5 million people who died in this country on 2014 were in hospice care. In 2014, an estimated 1.6 to 1.7 million patients received services from hospice. About $80 \%$ ended their lives in hospitals connected to the latest in medical technology. However, perhaps twice as many patients should have been in hospice programs, according to specialists in the field. In 2014, approximately $84 \%$ of hospice patients were 65 years of age or older with $41.1 \%$ being 85 years of age or older. More than half of hospice patients are female (53.7\%) with $46.3 \%$ being male. When hospice care in the United States was established in the 1970s, the largest percentage of patients had cancer as a diagnosis when admitted. In 2014, less than half of the patients admitted were diagnosed with cancer. The majority of deaths were due to other terminal diseases. The top four non-cancer diagnoses for patients admitted to hospice were dementia (14.8\%), heart disease (14.7\%), lung disease (9.3\%), 
and stroke or coma (6.4\%). ${ }^{20}$ Pediatric patients account for less than $1 \%$ of patients. Pediatric palliative care programs are increasing with $20 \%$ of hospice programs actively providing or developing pediatric palliative care programs. ${ }^{21}$ In the last decade about 40 perinatal hospice programs have been started in the United States. Perinatal hospices are for those families who give birth to babies with fatal anomalies. Statistics show that $20 \%$ to $40 \%$ of parents given a diagnosis of a fatal fetal condition do not opt to abort the fetus but to carry the fetus to term. Perinatal hospices help families gain control over an event that could be devastating. In general, parents allow these babies to die without aggressive medical intervention, including feeding tubes, intravenous fluids and surgeries. They allow for medications to ease the child's discomfort. Most of these children die within hours of birth but about $30 \%$ go home with their families where they eventually die. ${ }^{22}$

In 2014, the median length of service was 17.4 days, a decrease from 18.5 in 2013. This means that about half the hospice patients received care for fewer than 17 days and half received care for more than 17 days. The average length of service decreased from 72.6 days in 2013 to 71.3 in 2014. In 2014, larger proportions of hospice patients (approximately 35.5\%) died or were discharged within seven days of admission when compared to 2013 (34.5\%) In addition, larger proportions of patients died or were discharged within 14 days of admission when compared to 2013 (50.3\% and $48.8 \%$ respectively). ${ }^{23}$ Very little comfort and support can be given to patients and family members in such a short period of time. This is frustrating not only for the patient and family but also for the hospice personnel.

Another interesting statistic is that only one in five patients admitted to hospice care is a minority. $76.0 \%$ of hospice patients are white, 7.6\% African American, Hispanic/Latino $7.1 \%$ and $13.1 \%$ other. The percentage of minority patients accounted for about one quarter of hospice patients in $2014 .^{24}$ There are many reasons for the low number of minorities ranging from mistrust of the medical profession dating back to the historical atrocities when Black Americans were denied adequate health care or were used as laboratory guinea pigs without their knowledge as in the Tuskegee Syphilis Study ${ }^{25}$; to not wanting strangers in their homes, to their spiritual tradition that believes God not a doctor determines who lives and who dies; to their belief in miracles. Many African Americans will opt to die in a hospital because they believe only there will they get all the treatment the medical profession has to offer like the whites receive. This is why African Americans and other minorities are less likely than whites to consent to DNR orders or to write Advance Directives or Living Wills. Much of the research on ethnic and racial influences on end-of-life decision-making is based on anecdotal information. What is needed is evidence-based research so that recommendations can be made to develop strategies for integrating cultural specific components into end-of-life care. ${ }^{26}$ Unless something is done to overcome these suspicions, African Americans and other minorities will continue to receive less palliative care at the end of life.

In 2015, the United States health care spending increased 5.8\% to reach $\$ 3.2$ trillion or $\$ 9,990$ per person. The percentage of patients covered by the Medicare Hospice Benefit (versus other payment sources) increased to $85.5 \%$ in 2014 . The percentage of patient days covered by the Medicare hospice benefit versus other sources was $90.3 \%$ In addition to Medicare and Medicaid funding, the other sources of hospice revenue are private insurance companies, and community donations and grants. It is believed that due to our aging population and an increasing interest and concern for end-of-life care and rising health care costs, the need for Medicare-certified hospices will continue to grow. ${ }^{27}$ Despite these costs, hospice care is still more costeffective than hospital and skilled nursing care facilities. There have been various studies on the cost-effectiveness of hospice care, both federally and privately sponsored, which provide strong evidence that hospice is a less costly approach to care for the terminally ill.

One of the biggest deterrents for individuals in regards to hospice is that most individuals with a terminal condition who wish to enter hospice care must forego advanced medical treatment to qualify for hospice care. This means cancer patients, under most circumstances unless it is for palliative care, must pass up chemotherapy; and patients with kidney failure must abandon dialysis. This either-or decision has caused some patients who would greatly benefit from hospice care to opt for aggressive treatments in the hospital which are far more costly. Recently, some hospice programs and private health insurers have initiated a new approach called "open access" to encourage patients to get on hospice for their last months of life. This new approach allows hospice programs to offer advanced medical treatment even when they are not paid more to do so. Proponents argue that it is an example of the efforts of some insurers and health care providers to try to fix specific problems in the nation's medical system. Insurers like Aetna and United Health are allowing some patients to have potentially life-prolonging medical treatment while on hospice. Physicians argue that the either-or approach is less valid today in that continued advances in medicine are allowing even patients with very advanced diseases to benefit from new treatments. The Aetna experiment allows 40,000 of its roughly 15 million insured members to be eligible for these services. The initial results have shown that people will take 
advantage of hospice care if they do not have to give up other treatments to prolong their life. In the long run this will be cost effective and it allows patients more time to take advantage of hospice benefits. The Aetna experiment is the exception and Medicare still requires patients to give up regular medical coverage if they enter the hospice program. Opponents argue that this experiment is misguided because it causes patients to spend their last days in a hospital receiving expensive care that may not even be beneficial. Many hospice programs are too small to spread their costs, which would allow them to take patients needing expensive treatments. Some are arguing that Medicare should drop its requirement that patients forego other coverage if they want hospice care. Senator Ron Wyden of Oregon has introduced legislation that would end the Medicare requirement. He argues that the change would not significantly raise Medicare spending, but that it would give people more control over the way they die. Aetna plans to continue this experiment, because in the first year the average length of stay in hospice increased to 34 days up from 27 days. Aetna may in fact end up extending its coverage to more of its insured members. ${ }^{28}$

Most hospices are run by nonprofit, independent organizations. Some are affiliated with hospitals, nursing homes or home health care agencies, and there are some that are for-profit organizations. Determining which hospice would be best for a patient may take some research. Most patients and families hear about hospice from their physician or nurse or social worker. One can also find information about hospices from the National Hospice and Palliative Care Organization [http://www.nhpco.org/templates/1/homepage.cfm ], state hospice organizations, or the state health department. The telephone number for state hospice organizations and health departments can be found in the state government section of the local telephone directory. The Medicare hotline can also answer general questions about Medicare benefits and coverage and can refer people to their regional home health intermediary for information about Medicare-certified hospice programs. The toll-free telephone number is 1-800-MEDICARE (1-800-633-4227). Deaf and hearing impaired callers with TTY equipment can call 1-877-486-2048. The booklet Medicare Hospice Benefits is the official publication for Medicare hospice benefits. The booklet, which outlines the type of hospice care under Medicare and provides detailed information about hospice coverage, is available at http://www.medicare.gov/ Publications/Pubs/pdf/02154.pdf on the Internet. Information about Medicaid benefits can be accessed at http://cms.hhs. gov/medicaid on the Internet. ${ }^{29}$ It is recommended that when evaluating hospice programs the following questions should be addressed:
1) Is the hospice Medicare-certified?

2) What services are available to the patient?

3) What services are offered to the family?

4) What bereavement services are available?

5) How involved are the family members?

6) How involved is the doctor?

7) Who makes up the hospice care team, and how are they trained and screened?

8) How will the individual's pain and symptoms be managed?

9) If circumstances change, can services be provided in different settings? Does the hospice have contacts with local nursing homes? Is residential hospice available?

10) Is the program reviewed and licensed by the state or certified in some other way?

11) Are all costs covered by insurance ${ }^{30}$

Finding the right hospice for a patient is essential. It is important that patients and family members examine the available options and select the hospice that is the most advantageous for the particular individual in his or her condition.

The general consensus is that hospice care is very beneficial for both patients and family members but it is not without its critics. Felicia Ackerman argues that some of the principles of hospice care depend on a highly questionable ideology that while valuable to some terminally ill patients, can be reasonably rejected by others. She uses as an example the fact that hospice is not religiously based, but she argues that it does seem to have a religious foundation. Although serenity in the face of impending death is reasonable for those who are confident of the afterlife, she asks why should those individuals who believe their death will be the unequivocal and permanent end of their existence expect such serenity. Ackerman questions whether such expectations constitute an attempt to export religious based attitudes. Ackerman also argues that "when its principles are fully scrutinized and understood, hospice care will be seen, not as 'the most effective route to a dignified death,' but as just one option for the terminally ill, whose other options should include experimental attempts at a cure, high-tech life-prolongation, and perhaps even assisted suicide." ${ }^{31}$ This position is based on giving all terminally ill patients the right to choose any option of treatment. What Ackerman fails to consider is that some of these options are neither in the best interest of the patient nor in the best interest of society as a whole. Medical resources are limited and using these resources on patients who will not benefit from them violates both the ethical principle of beneficence and the principle of justice because this is not a 
just allocation of resources.

Despite all the services that hospice offers to patients and families, it is still one of the best kept secrets in hospitals, nursing homes and among those who are terminally ill. There are many reasons for this ranging from the patient's fear of accepting death, to the family's pressure on the patient not to give up hope, to physician's denial that there is nothing more that can be done for the patient clinically. However, there seems to be a trend in the United States that as more patients and families become educated about the benefits of hospice and palliative care it is becoming more of a viable option than dying in a hospital attached to the latest advances in technology. Hospitals and nursing homes need to initiate Palliative Care Policies not only to benefit patients but to encourage physicians, nurses and social works to make palliative and hospice care a priority for all terminal patients [Appendix $\mathrm{F}$ : Sample Palliative Care Policy]. For hospice and palliative care to become a viable option for the terminally ill, physicians, nurses and social workers need to initiate conversations about the benefits of these programs at the appropriate time. When a patient has been diagnosed with a terminal condition and further medical treatment would appear not to be beneficial, that is the time to begin the conversation. Patients and family members often need time to digest the fact that the disease process has moved from a curative mode to a palliative mode of care. Besides initiating such a conversation, physicians also need to take the time to listen to patients and their loved ones so that they truly comprehend how much the patient and family members understand and what are the values that are forming their decision-making. Physicians need to help patients walk their final journey with dignity, peace and compassion, as well as supporting their loved ones throughout the process. ${ }^{32}$ Recent studies have shown "lower morbidity and mortality and better emotional support among surviving family members of hospice patients than among family members of patients who did not receive hospice services, although it is uncertain whether this difference reflects the nature of families who elect hospice care rather than the effects of the intervention. ${ }^{33}$ The advantages of hospice and palliative care have been shown to benefit not only patients and family members but also society as a whole. Until health care professionals, patients and families become more comfortable talking about the death and dying process, the fear is that hospice and palliative care will remain marginalized as an excellent option for accessing supportive services during an extremely difficult time. ${ }^{34}$ Hospice and palliative care can no longer be viewed as abandonment and giving up hope; instead it has to be seen as getting the care that the patient and the family desperately need.

\section{Palliative Care and Hospice in Developing Nations:}

In the United States and in most Developed Nations, Palliative Care and Hospice, when utilized in a timely manner, offer great advantages to patients and their loved ones in end-of-life care. In many ways, hospice does more for families and friends of the patient then it does for the patient. The patient has his/ her symptoms managed and their quality of life is of the highest caliber, but family and friends are often over looked at this crucial time. Hospice provides the needed support and counseling for loved ones so that they can continue be present to the patient, But more importantly, hospice helps loved ones to face the inevitability of death in a realistic and loving way. This support and counseling continues for at least 6 months after the death of their loved one.

Palliative care and hospice in the United States can serve as a paradigm for developing nations. Understanding the challenges that are faced in the United States can better prepare other nations to overcome the negative aspects and concentrate more on the positive aspects. Many of the challenges faced in the United States will be present in other nations. Death and dying has social, cultural and religious dimensions among all types of peoples. Lessons learned in the United States can be adapted to other cultures and religions and many of the challenges faced in the United States can be overcome by preparing people to face dying and death realistically and providing comfort measures as an integral part of end-of-life care. With the proposed implementation of Palliative Care and Hospice Care in developing nations, the dignity and respect of all human life, even in its last moments, would be protected and the greater good would be promoted.

\section{REFERENCES}

1. Cousins, N., 1979. Anatomy of an Illness as Perceived by the Patient: Reflections on Healing and Regeneration. WW Norton \& Company.

2. Morrison, R.S. and Meier, D.E., 2004. Palliative care. New England Journal of Medicine, 350(25), pp.2582-2590.

3. Editor. "Hospice Facts \& Statistics," Hospice Association of America (Washington, D.C.: 2006): 1-11. http://www. nahc.org/Consumer/hpcstats.html

4. Williams, E., 2015. A Bioethical Consideration of End of Life Care.

5. World Health Organization. "Definition of Palliative Care," (World Health Organization: 1990). http://www. who.int/cancer/paliative/definition/en/) Retrieved on December 12, 2006. 
6. Editor. "What is Hospice?" American Cancer Society (August 2004): 1-4 at 1. http://www.cancer.org/ docroot/eto/content/eto $25 \mathrm{x}$ what is hospice care. asp?

7. Taylor P. "Hospice: Caring When There Is No Cure," Advance For Nurses (February 1, 1999): 20.

8. Mayo Clinic Staff. "Hospice Care: An Option for People with Terminal Illness," Mayo Clinic (April 17, 2006): 1-4 at 1. http//www.mayoclinic.com/health/hospice-care/ $\mathrm{HQ} 00860$

9. Meldrum M. "A Capsule History of Pain Management," Journal of the American Medical Association 290, 18 (November 12, 2003): 2470-2475 at 2473-2474.

10. Editor, "Hospice Facts \& Statistics," at 1.

11. Editor, "Hospice Facts \& Statistics," at 2.

12. Center to Advance Palliative Care. "A Guide to Building a Hospital-Based Palliative Care Program," (2006). www. capc.org.

13. Centers for Disease Control and Prevention, "Hospice Care," July 6, 2016. https://www.cdc.gov/Other/ plugins/\#pdf.

14. Editor. "NHPCO's Facts and Figures - 2005 Findings," National Hospice and Palliative Care Organization (November 2006): 1-3 at 1. www.nhpco.org/files/ public/2005-facts-and-figures.pdf

15. Morrison, R.S. and Meier, D.E., 2004. Palliative care. New England Journal of Medicine, 350(25), pp.2582-2590.

16. Ackerman, F., 1997. Goldilocks and Mrs. Ilych: A Critical Look at the "Philosophy of Hospice". Cambridge Quarterly of Healthcare Ethics, 6(03), pp.314-324.

17. Care, H., 1998. A Physician's Guide. Arlington, VA: National Hospice Organization.

18. Connor, S.R., Tecca, M., LundPerson, J. and Teno, J., 2004. Measuring hospice care: the National Hospice and Palliative Care Organization national hospice data set. Journal of pain and symptom management, 28(4), pp.316-328.

19. Kirk, T.W. and Mahon, M.M., 2010. National Hospice and Palliative Care Organization (NHPCO) position statement and commentary on the use of palliative sedation in imminently dying terminally ill patients. Journal of pain and symptom management, 39(5), pp.914-923.
20. Editor, "NHPCO Facts and Figures-Hospice Care in America," 2015 at pp.3-6.www.nhpco.org/nds.

21. Editor, "NHPCO's Facts and Figures-Hospice Care in America," 2015 at 6.

22. Banerjee N. "A Place to Turn When a Newborn Is Fated to Die," New York Times (March 13, 2007): 1-6. http:// www.nytimes.com/2007/03/13/health/13hospice. html? $r=1 \&$ th=\&oref=slogin\&emc

23. Editor, "NHPCO's Facts and Figures-Hospice Care in America," 2015 at 5.

24. Editor, "NHPCO's Facts and Figures-Hospice Care in America," 2015 at 7.

25 Waldman H. "A Last Compassion Resisted," Hartford Courant (January 29, 2006): 1 and 44.

26 Editor, "NHPCO's Facts and Figures-Hospice Care in America," 2015 at 10.

27. Abelson R. "A Chance to Pick Hospice, and Still Hope to Live," New York Times (February 10, 2007): 1-5. http:// www.nytimes.com/2007/02/10/business/10hospice. html

29. National Cancer Institute, "Hospice Care," 2012. https:// www.cancer.gov/about-cancer/advanced-cancer/carechoices/ho

30. Daugherty, C.K. and Steensma, D.P., 2002. Overcoming obstacles to hospice care: an ethical examination of inertia and inaction. Journal of Clinical Oncology, 20(11), pp.2752-2755.

31. Ackerman, B., 1980. Social justice in the liberal state (Vol. 401). Yale University Press.

32. Mulvihill, N., 2004. Giving Patients a" Good Death": A New Hampshire Facility Describes the Development of Its End-of-Life Care Program.

33. Teno, J.M., Clarridge, B.R., Casey, V., Welch, L.C., Wetle, T., Shield, R. and Mor, V., 2004. Family perspectives on end-of-life care at the last place of care. Jama, 291(1), pp.88-93.

34. Wachterman, M.W., Marcantonio, E.R., Davis, R.B. and McCarthy, E.P., 2011. Association of hospice agency profit status with patient diagnosis, location of care, and length of stay. JAMA, 305(5), pp.472-479. 